\title{
CANTOS Y ENCANTAMIENTOS EN LAS OBRAS FONOGRÁFICAS DE MILTON NASCIMENTO
}

\section{CHANTS AND CHARMS IN PHONOGRAPHIC WORKS OF MILTON NASCIMENTO}

\begin{abstract}
Alberto Carlos de Souza ${ }^{*}$
RESUMEN

Esta obra, con la propuesta de conducir el concepto de lugares de memoria, se realiza un estudio de dos obras fonográficas de Milton Nascimento, "Minas" y "Geraes", puesto en marcha, respectivamente en 1975 y 1976 y se considerados críticos por el día como la mejor traducción del "movimiento" Clube da Esquina en sus propuestas, las representaciones culturales, la musicalidad y la poesía como expresión de la autonomía del grupo (no hay que olvidar que el propio Milton, a pesar de su Inglés roto, se haciendo la fama en el extranjero y no se asimila las influencias de música más actual en Norteamérica y Europa). Estas obras se generó un contexto en el que Brasil fue un momento de fuertes presiones políticas, debido a que Milton Nascimento y sus compañeros se dan cuenta el tiempo para cantar en "Minas" en el canto, sus raíces en la minería y en "Geraes" cantar, al tiempo que incorpora elementos de la musicalidad de América Latina.
\end{abstract}

Palabras- clave: Milton Nascimento. Música popular brasileña. Identidad cultural.

\begin{abstract}
This work, with the proposed driving the concept of places of memory, a study is made from two phonographic works of Milton Nascimento, "Minas" and "Geraes", launched respectively in 1975 and 1976 and were considered critical by the day as the best translation of the "movement" Clube da Esquina in their proposals, cultural representations, musicality and poetry as an expression of group autonomy (can not forget that Milton himself, despite his broken English, was making fame abroad and there was assimilating the latest music influences of North American and European). These works were engendered a context in which Brazil was a time of strong political pressure, due to which Milton Nascimento and his partners realize the time to sing out in "Mine" into singing, rooted in mining and in "Geraes" sing out, while incorporating elements of its Latin American musicality.
\end{abstract}

Keywords: Milton Nascimento. Brazilian Popular Music. Cultural identity. 


\section{Introducción}

Este estudio - un diálogo entre la História y la Cultura - trató de presentar un momento de la música brasileña en un contexto histórico que se presenta en la década de 1970, se enfrenta, mientras que la biografía (musical y personal) de Milton, teniendo como punto de partida los discos de "Mine" y "genera". Milton era - y sigue siendo - la mayor referencia de lo que algunos autores llaman un "movimiento de resistencia" cultural. De toda la discografía extensa de Milton Nascimento, nuestra elección fue el "Minas" (1975) y “Geraes" (1976) las obras consideradas por la crítica como la producción musical más representativo del movimiento del club de la esquina.

El denominado "Clube da Esquina" estalló en Minas Gerais en 70 años, una época en que Brasil estaba bajo el signo de un régimen autoritario. Por otra parte, estas obras permiten una interpretación que pone de relieve el tema de la identidad. "La lectura de las cartas anunció un movimiento de ir y venir, una" internalización "y una" alienación "y nos permite hacer una lectura de la música compuesta por Milton Nascimento en el que el artista se ha abierto para la nueva sin perder su identidad local.

Así, Hall (2006) cree que este tiempo en que vivimos, marcado por la globalización, la crisis de identidad es inevitable. Tal estado de crisis permite a los individuos para identificar nuevas posiciones, por lo menos las identidades fijas y unificada, pero abierto a las nuevas, sin renunciar a su cultura, por lo que es posible aprender nuevos conocimientos, que es irreversible en este proceso - llamado globalización - abierto a la diversidad. En pocas palabras, creemos que se debe a la escuela por los estudiantes para crear un espacio para la recuperación de su patrimonio cultural y para ello, consideramos que la teoría de los lugares de memoria - como propuesta de Nora (1984) y discutir el lugar de la memoria en su poesía Minas “ “(1975) y” Geraes “(1976). La teoría de los lugares de la memoria fue formulado y desarrollado a partir de seminarios dirigidos por Nora en la Ecole Pratique de Hautes Etudes de París entre 1978 y 1981, y publicado en "Les Lieux Recuerdos", una obra compuesta de cuatro volúmenes. En referencia a la memoria nacional francesa, Nora, en este trabajo, es importante hacer un inventario de los lugares donde la memoria - cada vez más en peligro de extinción - sigue siendo rojo. También se debe considerar que el concepto pedagógico actual, hay una inseparabilidad de la educación y la cultura,

[...] porque a educação como formação e instrumento de participação precisa partir das potencialidades do educando e motivá-lo à criatividade própria. A cultura constitui o contexto próprio da educação, porque é motivação fundamental para a mobilização comunitária e quadro concreto da criatividade histórica (DEMO, 1993, p. 58).

\section{En cuanto a la cultura, Laraia (2005), concluye que,}

[...] cada sistema cultural está sempre em mudança. Entender esta dinâmica é importante para atenuar o choque entre as gerações e evitar comportamentos preconceituosos. Da mesma forma que é fundamental para humanidade a compreensão das diferenças entre povos de culturas diferentes, é necessário saber entender as diferenças que ocorrem dentro do mesmo sistema ( LARAIA, 2005, p. 101).

La historia de la cultura, a pesar de que es una cadena francesa de hacer historia. Fruto de la tradición de la escuela de los Annales, la difusión mundial de algunos autores, a veces se confunde con la Historia de la Nueva Historia Cultural, un término acuñado por Jacques Le Goff para el historiador de los Annales en la década de los 70, “[...] teniendo en cuenta el papel principal de los historiadores franceses, la historia cultural se puede considerar hoy en día una historia sin fronteras, con la difusión en todo el mundo. "(PENSAVENTO, 2008, p. 99).

En el campo de la música, Adorno cree que lo mismo, aunque similares, no es un lenguaje, ya que cuenta con un sistema de signos:

[...] A música assemelha-se com a linguagem na qualidade de sequência temporal de sons articulados, que são mais do que meros sons. Eles dizem algo, frequentemente algo humano. Dizem tão mais enfaticamente, quanto mais à maneira elevada estiver a música. A sequência de sons converteu-se em lógica: existe certo ou errado. Porém, aquilo que foi dito não pode se depreender da música. Ela não compõem nenhum sistema de signos (ADORNO, 2008, p. 1). 


\section{Metodología}

Nuestras fuentes fueron los registros de estudio "Minería" y "Geraes" liberados respectivamente en 1975 y 1976, entrevistas y libros sobre el tema de la vida y la obra de Milton Nascimento. Donde sólo se utilizan las canciones compuestas por Milton y sus socios están en "Mine" del LP (1975) y "Geraes" (1976), grabado por los estudios de EMI / ODEON, las canciones seleccionadas fueron: Blind Faith, un cuchillo afilado, Saudade aviones Panair, Gran Circo, Ponta de Areia, Trastevere, la idolatría, la clase y Bebeto, muchacho, Promesas del Sol, la Luna se volvió, Circus Hornet, Primero de Mayo, el CIO de la Tierra.

El concepto de los lugares de memoria, como la concepción de Nora (1992) fue el faro que orienta el informe. La teoría fue formulada Lugares de la memoria de los seminarios dirigidos por Pierre Nora, entre 1978 y 1981, la École Pratique des Hautes Etudes - en París. A partir de 1984, bajo su dirección, se inició la publicación de "Les lieux de mémoire", una obra que, a partir de la observación de la rápida desaparición de la memoria nacional francesa, el inventario de propuestas de los lugares donde realmente se sigue en rojo gracias a la voluntad de los hombres y, a pesar del paso del tiempo. Nora (1992) símbolos, fiestas, símbolos, monumentos, la celebración, la alabanza, diccionarios, y los museos son lugares de memoria.

Milton Nascimento (Bituca o, si el lector prefiere) es reconocido a nivel nacional como un icono de la mía. Pero es un error pensar que nació y se crió en el barrio bucólico de Santa Teresa, en Belo Horizonte. Milton nació en el barrio de Tijuca, Rio de Janeiro, el 26 de agosto de 1942. ¿Pero quién era este niño? Podría ser, como él nos dice Del Priore (2007), un niño al igual que muchos otros niños brasileños, como los que están en todas partes, con diferentes destinos y se enfrenta a variadas: mulatos caritas, negros, blancos y mestizos. Algunos otros simplemente amaba o usado. Milton era hijo de María do Carmo, una criada que se produjo en Minas que trabajó en casa de la pareja Silva Carvalho, pero murió de tuberculosis cuando el niño víctima tenía sólo un año. Una de las hijas de esta pareja, de nombre Lilia, como se detalla a continuación, sólo asumiendo la creación del niño.
En cuanto a la inclusión de las mujeres de las clases bajas en el lugar de trabajo, como fue el caso de Maria do Carmo, niña negro y provincial, debemos tener en cuenta que, históricamente, siempre han sido presionados a pagar más Maids “[ [...] ( ...) han existido desde el fin de la esclavitud. En el campo, las mujeres siempre han estado presentes en el cultivo, sólo mirar cualquier ilustración de los cultivos de café o caña de azúcar con el fin de ver ... "(Souza, 1997, p. 182). Tratando de analizar la situación de la mujer en el siglo XIX, la ciudad de Río de Janeiro, en particular con respecto a las actividades laborales, Leite (1984) registró a partir de una selección de documentos de ese siglo, tomada de los libros escritos o traducidos al portugueses, los esclavos, y el servicio doméstico o trabajan en los campos, también fueron utilizados como portadores de agua, mojado con leche, lavanderas, vendedores o arrendatarios. Este autor encontró, también, a partir de registros Gendrin, con fecha de 1817, que las mujeres (blanco) de Brasil, así como perezosos, fueron mucho más crueles que los hombres, la tarea de "educar" a sus hombres y mujeres negro.

Bueno, con la muerte de Maria do Carmo poco Bituca fue enviado a casa de su abuela en Juiz de Fora. Mientras tanto, Lilia se casa y se va a vivir en la ciudad de tres puntos en el interior de Minas Gerais. Estrechamente ligada a la pequeña Bituca sólo se calmó cuando obtuvo la custodia del niño.

Este lazo de amistad que nació entre Bituca y una vez fortificado Lilia, se extendería a todas las mujeres. Más tarde, con la ayuda de Fernando Brant, Milton hizo una canción de agradecimiento a la mujer. En el "reverenciado" (nacimiento, Brant, 1975), una mujer tiene muchas cualidades que Bituca aprendido a reconocer en Lilia: ella es el hogar de valientes, el cuidado y la familia, amigo y verdadero. El fragmento de la letra de esta canción, que presentamos a continuación, da cuenta de esto: "Grande es grande su valor, su amor (...) Usted es una mujer, cuidar del hogar y la familia ...”.

Por primera vez, un tren que parece pequeño en la vida de Milton. Después de haber ido a Juiz de Fora buscar al niño, Lilia y su esposo Josino la Zino - nos alojamos en Río de Janeiro. De Río de Janeiro Tres consejos para el viaje fue en tren. Zino, perdido en la lectura de una novela. Lilia infectados con la alegría de Bituca, porque era 
como si estuviera jugando en un viaje de tren Grit Little. En, la nostalgia, Lilia recordó la época en que estudiaba en escuelas públicas y fue un estudiante de Villa-Lobos. "Ahí va el tren con la (...) muchacho de las colinas, pasando por el mar" (Sadie, 2002). El encanto que tenía para los tranvías en Río de Janeiro fue trasladado automáticamente a los trenes. Muchos años más tarde, junto con Fernando Brant, Milton estaba recuperando de sus recuerdos la memoria de este viaje, una de sus canciones, hablando de otro ferrocarril, citado por ellos como un camino "natural" que une Minas a la mar, que son hablando del ferrocarril Bahía-Minas, construida a finales del siglo XIX y séuclo fuera en los años 60 , quien vinculó al oeste de Minas Gerais hasta el sur de Bahia (história da ferrovial Bahia-Minas, 2008). Fue la canción "Ponta de Areia" (nacimiento, Brant, 1975).

Que viaje en tren, que fue el primero en tres puntos, Bituca también encantado por las montañas y plantaciones de café. Sumado a esto, durante los años que vivió en esa ciudad, el encanto de las leyendas contadas por sus abuelos paternos, el amor de su madre, los inventos de su padre, minero religión, las sesiones de los alimentos trivial para el domingo cine, jugar con otros niños y con sus juguetes más grande - la música. Todo esto formaba parte del pasaje de Milton a los mineros - sentimiento o sentido de la particularidad de ser la minería camino. Manera de ser un minero, una cosa que brota de la tierra ", el CIO de la tierra" (nacimiento, Holanda, 1976), en la que el trigo nace que forja el milagro de los panes, que las chuletas de la caña, y su dulzura robados si untado con miel.

Las casas que vivió en tres puntos, Milton tiene buenos recuerdos de los patios que lo tenía todo - palos, piedras, latas - carriles y se volvió a la entrada de un tablero lleno de luces, anuncia Maribondo Circus. Camión de sonido en la calle y los niños en un alboroto.

$\begin{array}{ccccc} & \text { El } & \text { payaso en } & \text { buena } & \text { forma } \\ \text { pide a los niños: Hoy es el jam? }\end{array}$ Perdido en los recuerdos de un tiempo que no vuelve jamás, Milton Nascimento y el sueño de Ronaldo Bastos, mientras garabateaba las letras "Circo marrinbondo" Yo he venido desde lejos, no me atrapaia (nacimiento, Bastos, 1976).
En otros lugares este tiempo nunca vuelve, Milton - ahora con Borges Márcio - sin dejar de hablar sobre el circo. Otro circo, el hombre del circo, en el que el payaso, corre el riesgo de que puede ser simbólica o real. Como advierte Goudard (2009, p. 25), el circo, "La vida se pone en juego en la escena, y la muerte - a ser juzgado? - Es cierto y se llama a mundo ". En el "Gran Circo" (nacimiento, Borges, 1975), Márcio Borges y Milton parecen reducir el mundo a un escenario en el que todos podemos ser payasos y bailarines hambre loco.

Milton tenía cinco años cuando ganó su primer instrumento fue una armónica una única escala. Así que comenzó a explorar la armónica que suena simple y no tenía nada para llamar la atención. Fue con su segundo instrumento musical, una armónica equipado con sostenidos y bemoles, la familia se dio cuenta de que "el chico tenía talento." Sin embargo, que estaba con su acordeón Bituca ganó fama como un niño, incluso antes de la edad de siete años, un acordeón "[...] Primera de dos bajos y bajos de la Hering cuatro sanfoninha (...). No tenía ni sostenidos o bemoles. El mecanismo para producir una nota musical cuando el acordeón se abre y otro para cerrarlo "(Duarte, 2006, p. 41).

Little Milton hizo todo sus primeros estudios en una escuela pública $\mathrm{y}$, curiosamente, llevaba el nombre de un sacerdote negro: era el grupo Canon Escuela Victor. Bituca vivía en la casa de su abuela materna, en Río de Janeiro, para hacer de la escuela secundaria (emparejado 5 al $8^{\circ}$ grado de primaria) en el Colegio Uruguay Tijuca. La abuela, la señora Augusta, había convencido a los padres del niño para estudiar en Río de Janeiro sería más beneficioso para su futuro. Una vez más, la tendencia estaba presente en la vida del niño, pero la discriminación era en su mayoría por chicos negro.

Por estos niños Bituca negro, porque viven dentro de una familia blanca, se oye con frecuencia insultos como "el mono" (Duarte, 2006). uno de sus mejores amigos hoy en día. En otra casa, en la misma calle donde vivía la familia Bituca, otro chico vivía encantado por la música. Su nombre Wagner - y, que es el hijo de un profesor de piano y el acordeón, estaba acostumbrado a vivir de la música todo el tiempo. El genio de la música de Bituca comienza en su primera infancia, desde la infancia han inventado sus propias historias y música. 
La participación de niños en la obra de Milton y su afecto por ellos está muy presente en su vida y obra. Milton tiene un hijo biológico, Pablo, nacido en 1972 y el resultado de su relación con Karita. Al parecer, Shea tuvo una gran importancia en la vida de Milton. Fue por Manoel Carlos (el novelista) y Elis Regina, mientras ve un concierto de Ray Charles en un club nocturno en Sao Paulo, que se reunió Milton Karita. La letra de la canción "Primero de Mayo" (nacimiento, Holanda, 1972), al hablar de una mujer cuyo cuerpo se compara con un taller en el que tejedor -, gira en las mallas de su vientre que de un nuevo mañana, parece sido hecha bajo la inspiración embarazada Shea. Sin embargo, Milton dice que no tiene uno, sino muchos niños: "La gente dice, 'Oh, tu hijo ...'. En lugar de un niño, voy a tener que sembrar miles Cada vez que algo me toca. Traigo cerca. "s de música como la vida en el escenario" (Vianna, 2006).

Suponemos que este gusto por Bituca repente adquirió de su padre - Señor Josino. Una de las historias cantadas por Bituca "Porcolitro", terminó siendo el trespontana chica bien conocida. Era la historia de un litro de leche y carne de cerdo resultó muchas aventuras protagonizada por el mundo. Durante ocho años, Porcolitro Bituca encantado la imaginación de los niños y trespontana todos. De siete a quince años de edad, Porcolitro, volvió a la vida, era una familia y preparado muchas aventuras. Sin embargo, se estaba haciendo tiempo para salir de la escena Porcolitro, Milton, poco a poco, deja atrás su infancia, y ella Porcolitro, y cuando era un adolescente comienza a recorrer el camino que te lleva por las bolas de la vida. En un camino con fe ciega, un cuchillo afilado. Un camino que comienza en tres puntos y dará, en un primer momento, en Belo Horizonte, y luego en todo el mundo. Brillo y pasando. Un paseo con muchos hermanos y hermanas de la fe. A la reunión, en 1975, con muchos de estos hermanos de la fe Ronaldo Bastos. ¿A dónde va a dar a este camino? En la música: "Blind Faith, un cuchillo afilado" (nacimiento, Bastos, 1975).

Bituca formó su grupo musical por primera vez como un adolescente, tenía sólo catorce años y todavía vivía en tres lugares. Los participantes en este grupo de cuatro amigos: Dida, Paul, Charlie y la Vera. El grupo se llamaba "La plata claro de luna" y fue inspirado por el grupo musical estadounidense The Platters. Con la entrada de Wagner Tiso grupo, nacido entre él y Bituca "[...] una alianza que duraría toda la vida. Milton Nascimento y composiciones de Wagner Tiso eran socios en la muestra, discos, juegos de bolas, en bancos de parques y bares "(Duarte, 2006, p. 57).

Las presentaciones de la "plata claro de luna" del grupo con Bituca en la voz, cada vez más frecuentes, y por lo tanto, el grupo sería conocido no sólo en tres puntos, pero en toda la región. El grupo llegó a grabar dos canciones para "The Platters" en el 78s. Los chicos se tomaron siempre por sus padres o tíos a los eventos donde se presentaron. Butt, además de acordeón y la armónica de juego, o vocal, ganó su instrumento abuela materna que se convertiría en su marca registrada: una guitarra. Butt pronto a dominar el arte de tocar la guitarra y, por tanto, el instrumento se inserta en el grupo musical. Poco a poco el grupo "Silver Moon" se deje de existir porque sus miembros, a excepción de Bituca había, por varias razones, la ciudad cambió. Bituca formó un nuevo grupo, titulado "Milton y toda una" y el debut de la misma ocurrió en el Automóvil Club de Tres Puntas. Milton fue el segundo año de estudio de cursos técnicos de Comercio, en tres puntos, cuando fue reclutado para servir en la Escuela de Sargentos de Armas (ESA), Tres Corazones en el servicio militar.

Vivir en Alfenas, Wagner Tiso fundó un grupo de muchachos bien llamado W: todos los miembros - Wagner, Waine, Wanderley y Wesley - tenía el nombre comienza con la letra W. Invitado por Tiso a participar en el fin de semana un grupo de cantantes, Bituca no tuvo más remedio que cambiar su nombre: Milton Nascimento se convirtió en el Wilton. El "Tamba Trio", formado por Luis Eca, Bebeto Castilho y Milito Helcio fue la gran referencia musical para este grupo. Después del servicio militar, regresó a tres puntos Bituca donde reanudó y completó el curso de operaciones comerciales. Aquí Milton cierra su ciclo de vida provincial. Y la aventura comienza muchos caminos de Milton. Un camino que va a dar los primeros en Belo Horizonte, la ciudad moderna. 


\section{Otras formas de ... Una forma fue a Roma}

En la antigua Roma, un río - el río Tíber. Trans Tiberim el Trastevere rione. En el Trastevere, una iglesia privilegiada - la Basílica de Santa Cecilia, la patrona de la música. En la misma Roma, en la iglesia de Santa María de la Victoria, una obra maestra absoluta, observado por Janson (1992) El éxtasis de Santa Teresa. En Belo Horizonte, la ciudad moderna en el barrio de Santa Teresa en éxtasis, Bituca el niño, que se había transformado en Wilton, vuelve a Milton: en silencio, escuchando y sonriendo como siempre. Siempre en compañía de muchos amigos. Junto con uno de ellos, Ronaldo Bastos, construido en los versos "Trastevere" (nacimiento, Bastos, 1975) moderna - la ciudad de Belo Horizonte.

En Belo Horizonte, siendo veinte, por primera vez Bituca fueron muy difíciles, porque nunca el niño quería depender económicamente de sus padres. Milton necesitaba un trabajo, ya que incluso en ese momento, yo no podría vivir en su música. Para sobrevivir, tiene un lugar de vendedor en un estado brasileño. En ese momento los hermanos Milton y Tiso - Wagner y Gileno - formó un trío musical llamado día de fiesta. La entrada de Milton y hermanos en Tiso "Balon Celio" tomó las manos del Pacífico Mascarenhas, considerada la mayor referencia de bossa novista minería en todo momento. Inmediatamente, Milton fue contratado como cantante famoso conjunto que fija, donde permaneció durante dos años.

Era el año 1963. Milton siguió participando en el conjunto aeronauta Celio, y el tiempo que queda todavía jugaba en el Holiday o que actuaciones como solista en los bares. Incluso con tantas ocupaciones encontró tiempo para formar el grupo Evolussamba, que jugó de samba en un club nocturno de Japón en Belo Horizonte. Justo antes de la temporada de vacaciones, Milton recibió la noticia de la enfermedad de su madre. Presa del pánico, hasta que recuerdo que ya en tres puntos, una mujer enferma correspondió a quedar embarazadas. Entre Navidad y Día de Reyes, que se celebra el 6 de enero, que pasó dos semanas en tres puntos, Milton tomó todo el interior la calma para reflexionar sobre el rumbo que quería darle a su vida: la música iba a sobrevivir o tendría que someterse a la monotonía de una oficina? De regreso a Belo Horizonte Milton continuó su mecanógrafa rutina - con cierto salario al final del mes - y músico - una buena cosa en su vida, pero el retorno financiero incierto.

Y ahí está el "Evolussamba" como algo inusual, un grupo de samba para tocar en un club en Japón. Todo esto parecía ser conjunto muy musical y en el hogar improvisado: los ensayos se llevó a cabo en una habitación de un edificio de apartamentos Levy - la residencia de los padres de Marilton Borges, uno de los miembros del conjunto. Sus padres, el Sr. y la Sra. Maricota Salim, vivía en el barrio de Santa Teresa, pero terminó cambiando, con la familia entera al centro de la ciudad. Aunque las pruebas se encuentran en "el baño de hombres," no hay en la casa de Borges, Milton no conocer a todos en esa familia. El grupo "Evolussamba" siguió su curso tocando samba de Clubes en Japón. En estas presentaciones, Danilo Vargas - Director y presentador de un programa de televisión el domingo en la minería - que los invitó a una presentación sobre "La tarde es nuestra", la Itacolomi TV desaparecida. El éxito fue tan grande, pero si dependiera de la timidez de Bituca, no habría pasado nada, que era de mala gana que se encontró con la empresa para jugar en la televisión.

En 1964, el comienzo de marzo, varias nubes se cernían sobre los estados de São Paulo y Minas Gerais, se instaló como una cálida brisa, un rumor, la caída del entonces Presidente de la República, Jango, por los militares. Pasado ese mes, el rumor se convirtió en hecho real y fue el general Castello Branco, que hizo una llamada a un amigo MP afirmando que "el proyecto de ley fue resuelto." Fue el comienzo de la dictadura en Brasil, situado en los 31 días de ese mes, pero que era para anunciar muchos hechos que han servido para aumentar la inestabilidad política, entre otros, el Paseo de los conservadores con Dios por la libertad y los movimientos de miles de personas en São Paulo y Minas Gerais, en protesta contra las medidas de política adoptadas por el presidente Jango (Gaspari, 2003).

Las manifestaciones estudiantiles, disturbios y ser instalado por el golpe militar ... Una ráfaga de eventos a la vez. Una nube gris se cierne sobre el cielo de la patria, dulce Madre. Preguntas, muchas dudas. Entonces el niño desaparece Bituca tímido, callado, dando tiempo a que el joven Milton, la 
conciencia crítica. Al componer, con su amigo Ronaldo Bastos, "Boy" (Nacimiento, Bastos, 1976), tallado a sangre y fuego, la bala rasga el pecho. El día 31 de marzo 1964 marcó el comienzo de uno de los períodos más críticos de nuestra historia. El mismo día, un club se estaba abriendo en el entresuelo de la maleta del edificio. Sin embargo, los clientes jóvenes de la construcción de la inauguración de la discoteca Berimbau maleta, después de todo, aún con vida o sin dictadura. Tocar o cantar en el club, era el sueño de cualquier músico de la ciudad, ya que sólo jugó casa "bestia”. Así, junto con Wagner y Paulo Braga Milton formó el "Trío Berimbau". Con esta capacitación fueron invitados a tocar en que era la sala de conciertos más prestigiosas de Belo Horizonte.

Belo Horizonte, al igual que todas las capitales de estado, tratando de adaptarse al nuevo régimen - la dictadura, y rodeado de soldados que aseguraron el orden y las buenas costumbres de la nación. Mientras tanto, en tres puntos, y todas las otras ciudades del interior de Brasil, la gente celebró el golpe militar en la creencia ingenua de que deshacerse de la amenaza del comunismo. La ciudad moderna, diseñado por el ingeniero Para Reis, en 1897, con el nombre de "Ciudad de Minas" está siendo eclipsado por la sombra de los militares. Exprimido, el joven Milton y Brant perdido el sueño del horizonte y la esperanza de recuperarla, hacer promesas. Promesa de la luz, el sol promesa profesional, la luna también pedir las cosas de los dioses de plata o profesionales griegos. Deambulando como zombies en una tragedia que agobia como un signo de resistencia a la opresión, Milton y Fernando Brant jota "Promesas del Sol" (Nacimiento, Brant, 1976).

Las presentaciones fueron programadas en el estadio para el Berimbau "Trio Berimbau" al final de cada semana. En los intervalos de la presentación del grupo, Márcio Borges, que estaba entre el público se acercó a Milton. Refinamiento intelectual del niño, en nuestra opinión, Márcio - una manera muy sensible - algo que había visto limitada la tensión psíquica de la cantante, informó Ostrower (1987, p. 27) como "una intensificación de la vida, una experiencia en el hacer. " Sencillo, sólo quería saber: ¿Qué está pasando? De esa conversación, al parecer, una obstrucción - a que se refiere a Milton, tales como dolor en el pecho - empezó a disiparse.
Esto también marcó el inicio de una relación muy intensa y fructífera colaboración entre ellas.

Este despertar se llevó a cabo de manera inusual: en una ocasión fue a ver a las dos de la tarde, una película: "Una mujer para dos" de Francois Truffaut. Un sábado perdió en 1964. Una tarde calurosa. Cómo pasar un tiempo en este momento? Disfrutando de una película. La sensación de placer siempre renovado al entrar en el Tupi, el cine más lujoso de Belo Horizonte. En la pantalla, Jeanne Moreau en el papel de Catherine, una mujer que estaba dudando entre dos hombres, protagonizada por Oskar Werner y Henri Serre. Como Truffaut insistió durante dos "[...] Una mujer es ante todo un personaje de la película "(Truffaut, 1990, p.128 - 129). Milton y Borges Marcio salió del teatro, a las diez, después de tres sesiones consecutivas y encantado con todo. En ese momento, el gran compositor nació. Para la alegría de Márcio Borges, Bituca propuso a su amigo: "[...] ¡Ven a tu casa ahora. Agarra una guitarra para mí, un papel y un lápiz, vamos a empezar a escribir. “(Duarte, 2006, p. 94).

Y luego, en un rapto, escribió una vez, tres canciones, muchas de las cuales podría tener todavía a partir de ahí, "La paz nace del amor" (Novena), "Spin, giró," y "creencia". Otro amigo, de gran influencia en su vida - Fernando Brant -. Con Brant, Milton firmaría muchas de sus canciones. Con estos dos amigos y muchos otros, todos tienen en común el amor por la música, es que el movimiento nació llamada "Clube da Esquina". Pero esa esquina estamos hablando? Nos estamos refiriendo a la confluencia de las calles y Divinópolis Paraisópolis, en el barrio de Santa Teresa en la ciudad de Belo Horizonte. Esa esquina era el "Bar Tuchão", donde Milton y sus amigos se reunían. De ahí la expresión "Clube da Esquina". Los principales miembros de este movimiento, podemos citar Milton Nascimento, Fernando Brant, Lô Borges y Marcio, Beto Guedes, Angelo Nelson, Wagner Tiso, Toninho Horta, Smith Robby, Novelli, Nivaldo Ornelas, Ronaldo Bastos Moura Tavinho y Murilo Antunes. Es, sin embargo, una lista incompleta.

En la ciudad moderna, sin embargo, sofocado por la dictadura, un grupo de jóvenes sentados en una mesa de bar. Cansado de la cerveza, decide, al menos en la noche - entre una conversación y otra 
- sólo beben Coca-Cola. Conversaciones acerca de qué? Montañas, trenes, vías, pequeñas iglesias. Además, en lugares comunes que llegan a pasar por la cabeza de Milton y Brant: cosas como, donde tomamos nuestra primera Coca-Cola? Se pierda el tiempo de vacas flacas que sólo podían viajar en autobús? Definitivamente no. Viajar ahora es sólo en los aviones. Señorita, entonces? Planes perder Panair (nacimiento, Brant, 1975).

Pero, según García (2000), que, estrictamente hablando, no Clube da Esquina "obtener" una esquina, pero en los escalones de la Tasa del edificio y los apartamentos. Como se mencionó anteriormente, en 1963, Milton vivía en una casa de huéspedes / apartamento en el cuarto piso de este edificio y en el piso diecisiete Borges vivió gran familia con muchos hijos, entre ellos, Lô y Marcio. Tener estos chicos el mismo interés en común - la música - la cercanía entre ellos era inevitable. La inclusión de Milton en la escena de música popular brasileña - como era común en su tiempo - fue a través de los festivales. Su primera aparición fue como cantante en el Festival Nacional de Música Popular de la TV Excelsior, en Sao Paulo, en 1966, cuando defendió la canción "ciudad vacía", escrito por Baden Powell. En este festival, el ganador fue el "buque insignia" de Vandre Geraldo y Fernando Lona, en la interpretación de la Tuca y Airton Moreira. "Ciudad vacía", ocupó el cuarto lugar y Milton, por su actuación, ganó el primer trofeo de su carrera: "Berimbau de Bronce".

Ese mismo año, Elis Regina incluye en su disco "Elis", publicado por el CBD-Philips, una de sus canciones - "Canción de sal", considerada por los críticos como su primera aparición importante como compositor. Con esta canción - y con la ayuda de Elis - Milton comienza a ganar prestigio: “[...] no era más que otra voz bonita, fue un compositor avant-garde, se dijo "(Duarte, 2006, p. 113). La ayuda de Elis fue decisivo y produjo a través de una invitación para participar en el programa de televisión (en vivo) "O Fino da Bossa", que fue, junto con Jair Rodrigues, presentador. En esta ocasión hizo un dúo con "Canción de la sal", tirando de una gran cantidad de aplausos del público.

Milton fue capaz de vivir razonablemente bien - compartían una habitación en una pensión con su primo Alligator - en Vila Mariana. Cuando el dinero había desaparecido, contó con el apoyo de ese primo que vivía en Sao Paulo para estudiar los "científicos". En esta ocasión, escribió: "Hermano de la fe", una canción que escribió en el Festival de Berimbau de Ouro.

Sin embargo, por lo que Milton ya no puede contar con el apoyo de la prima que había completado sus estudios. De regreso a Río de Janeiro, Milton fue la casa de Caetano Veloso, que solía visitar. Ese día fue especialmente triste. ¿Qué está pasando, dijo Caetano. Milton dijo estar triste porque sabía un par de amigos se habían separado. Milton empezó a tocar una melodía. Más tarde, en casa ahora, conseguir Bituca Caetano, comenzó tocando esa canción otra vez. Caetano lo presentó, en el acto, con la letra. Así nació "Paula y Bebeto" (nacimiento, Veloso, 1975), la historia de una pareja que se aman de todos modos, ya que "cualquier forma de amor vale la pena, de todos modos el amor es digna de ser amada."

Sentirse mejor, Milton regresó a St. Paul, aunque de mala gana amigos. "[...] Entendió que no podía volver a vivir en Beagá no quería. Por mucho que nos gusta allí, pensé que iba a dar el paso, ir hacia atrás "(Duarte, 2006, p. 115). A su regreso a San Pablo las cosas no fueron mejor y, por falta de dinero Milton llegó a ser casi una semana sin comer. Por primera vez en su vida, desde que había dejado tres puntos, Milton no le quedó otra alternativa que pedir dinero prestado a amigos y volver a casa. Son las tres Consejos visiblemente debilitado, lo que asustó a sus padres - Lilia y Zino.

De regreso a St. Paul, esta vez las cosas mejor que nunca: los estudios que han aparecido nuevos y nuevos amigos. Uno de ellos, el cantante Agostinho dos Santos, decidió apoyarlo. Y los Santos de San Agustín que Milton llegó a Río de Janeiro. Agustín señaló que, desde la desclasificación de "Hermano de la fe" Milton estaba decepcionado con la media de los festivales de música, para que nadie pudiera hacerle cambiar de opinión. Y las entradas para el Festival de la Canción Segunda Internacional (FIC) estaban abiertas. ¿Cómo asegurar la participación de Milton? La respuesta fue usar un dispositivo, pregunte a su amigo para grabar tres de sus composiciones en la cinta, en posesión de esa cinta, Agostinho dos Santos firmó Milton y las tres canciones en el FIC II. Fue a través de Elis Regina 
Milton sabía que era registrado en FIC y II, que es mejor clasificados.

En Río de Janeiro en la noche de la fiesta, Maracanãzinho estaba 1leno. Esta vez, a un público diferente, más colorido. En un lugar especial en las sillas de la pista, cerca del escenario, allí estaban: Lilia, Zino, la familia Brant y varias personas se acercaron a tres puntos. Entre ellos, su amigo de la infancia, Dida. El resultado de este festival, el balance fue muy positivo para Milton Nascimento: Crossing fue galardonado con el segundo lugar, Milton ganó el premio al Mejor Intérprete y fue el artista más aclamado del festival. Los días de "vacas flacas" que la cantante había llegado a su fin. Milton abrió el camino para la consagración. "Mine" fue creado en un momento de gran crisis financiera en la vida de Milton, de modo que ni siquiera él puede entender cómo él había creado algo tan claro.

De hecho, el álbum "Minas" resistido el paso del tiempo y la edad nunca en los últimos años, ya que su repertorio es constantemente revisada y reinterpretada por nuevos autores e intérpretes, con sus arreglos, la energía y el vigor de su repertorio (Bahiana, 2006). Mientras que "Geraes" era una especie de secuela de "Minas". Sin embargo, mientras que "mina" fue fiel a los mineros - los recuerdos, los paisajes, las pequeñas iglesias y trenes - "Geraes" incorpora elementos de las melodías de América a la minería. El resultado de la aclamada por la crítica, fue una fusión de ritmos de América Latina y del interior. Muchos amigos fueron convocados a la grabación de "Geraes". Esto sólo sirvió para dar fe del prestigio de Milton Nascimento, ya que algunos de ellos - ya conocido - que estaban allí para unirse al coro. Una mezcla de las voces de famosos y anónimos. Tenía amigos en todas partes: gente de la época del Club de la esquina, todos los participantes en la "La imaginación sonora" (ahora difunto), Miúcha, Toninho Horta, Bebel, Chico Buarque, Tavinho, Noguchi, Pii y otros. También participó en "Geraes", Mercedes Sosa, quien hizo un dúo con Milton en "Volver a deciesiete los" (escrito por Violeta Parra), el "Grupo del Agua", que participó en las canciones "caldera", "Promesas del Sol" y "Minas Gerais" y Clementina de Jesús, haciendo un dueto en "Circus Hornet". El LP "Geraes" junto con "Mis queridos amigos", de Chico Buarque son los discos más vendidos en 1976.

\section{Consideraciones finales}

Como dice la canción anterior, la vida de Milton Nascimento también se volvió, el niño experimenta fases como la Luna. El Bituca pequeña se estaba desvaneciendo, cuando perdió a su madre y fue enviado a Juiz de Fora. No era este el cuidado de Lilia, su nueva madre, le decimos a la historia anterior habría sido diferente, como la historia de muchos niños han llegado a su propia suerte.

Cuando, junto con Lilia y Zino, Bituca toma el tren a tres puntos, el niño experimenta su fase de crecimiento. Y cada vez más, el niño se llena. Lleno de afecto de sus padres y también lleno de creatividad, para descubrir y Porcolitro música.Por final Bituca se abre a lo nuevo. Al ir a vivir en Tres Corazones, donde sirvió al ejército, se convierte en Wilton. Más tarde, en Belo Horizonte, a su vez (otra vez) Milton. Y en el proceso, hace Milton Nascimento, caminando por una calle se llama el mundo.

\section{Referencias}

BAHIANA, Ana Maria. Nada será como antes: MPB anos 70 - 30 anos depois. Rio de Janeiro: Ed. SENAC, 2006.

BRZEZINSKI, I. (org). LDB interpretada: diversos olhares se entrecruzam. 7 ed. São Paulo: Cortez, 2002.

BORGES, Márcio. Os sonhos não envelhecem: histórias do Clube da Esquina. São Paulo: Geração Editorial, 1996.

DEL PRIORE, Mary. História da criança no Brasil. 6 ed. São Paulo: Contexto, 2007.

D'INCAO, Maria Ângela. Mulher e família burguesa. In: DEL PRIORE, Mary. (Org.). História das mulheres no Brasil. 9 ed. São Paulo: Contexto, 2008. p. 223 - 240.

DUARTE, Maria Dolores Pires do Rio. Travessia: a vida de Milton Nascimento. Rio de Janeiro: Record, 2006.

GARCIA, Luis Henrique Assis. Coisas que ficaram muito tempo por dizer: o Clube da Esquina como formação cultural. 2000. Dissertação (Mestrado em História) Programa de Pós-Graduação em História, Universidade Federal de Minas Gerais, Belo Horizonte, 2005.

GASPARI, Elio. A ditadura derrotada. São Paulo: Companhia das Letras, 2003.

GOUDARD, Phelippe. A estética do riso: do corpo sacrificado ao corpo abandonado. In: WALLON, Emmanuel $(\mathrm{Org}) . \mathbf{O}$ circo no risco da arte [Tradução Ana Alvarenga; Augustinho de Tugny; Cristiane Lage]. Belo Horizonte: Autêntica, 2009. p. 25-31. 
HALL, Stuart. Identidade cultural na pós-modernidade. Rio de Janeiro. DP\&A, 2006.

HISTÓRIA DA ESTRADA DE FERRO BAHIA-MINAS. Diário de Alcobaça - Bahia: guia virtual. Alcobaça, 4 ago 2008. Disponível em: www.alcobaca.bahia.net/2008/08/ vdeo-histria-da-estrada-ferro-bahia.html. Acesso em 6 set. 2009.

JANSON, H.W. História da arte. 5 ed. São Paulo: Martins Fontes, 1992.

LEITE, Mirian Moreira. A condição feminina no Rio de Janeiro - século XIX: antologia de textos de viajantes estrangeiros. São Paulo: Hucitec, 1984.

LIMA, Gilson. A sociedade e as culturas informacionais. SI. Disponível em: www.ufgrs.br/...sociedade/sociedade_ cultura/sociedade_info.ppt. Acesso em: 4 out. 2009.

NASCIMENTO, Milton. Milagre dos peixes. Rio de Janeiro: EMI/ODEON, 1973. 1 CD: digital, estéreo.

NASCIMENTO, Milton. Milagre dos peixes ao vivo. Rio de Janeiro: EMI/ODEON, 1974. 1 CD: digital, estéreo.

NASCIMENTO, Milton. Lua girou - arranjo e adaptação de Milton Nascimento sobre tema folclórico. In: NASCIMENTO, Milton. Geraes. Rio de Janeiro: EMI/ ODEON, 1976. 1 CD: digital, estéreo. 61.192.511

NASCIMENTO, Milton; BASTOS, Ronaldo. Clube da esquina. Rio de Janeiro: EMI/ODEON, 1972. 1 CD: digital, estéreo.

NASCIMENTO, Milton; BASTOS, Ronaldo. Fé cega, faca amolada. In: NASCIMENTO, Milton. Minas. Rio de Janeiro: EMI/ODEON, 1975. 1 CD: digital, estéreo. 61.245 .259

NASCIMENTO, Milton; BASTOS, Ronaldo. Menino. In: NASCIMENTO, Milton. Geraes. Rio de Janeiro: EMI/ ODEON, 1976. 1 CD: digital, estéreo. 61.192.481

NASCIMENTO, Milton; BASTOS, Ronaldo. Gran circo. In: NASCIMENTO, Milton. Minas. Rio de Janeiro: EMI/ ODEON, 1975. 1 CD: digital, estéreo. 61.274.774

NASCIMENTO, Milton; BASTOS, Ronaldo. Trastevere. In: NASCIMENTO, Milton. Minas. Rio de Janeiro: EMI/ ODEON, 1975. 1 CD: digital, estéreo. 61.247.782

NASCIMENTO, Milton; BASTOS, Ronaldo. Circo marimbondo. In: NASCIMENTO, Milton. Geraes. Rio de Janeiro: EMI/ODEON, 1976. 1 CD: digital, estéreo. 61.192 .473

NASCIMENTO, Milton; BRANT, Fernando. Saudade dos aviões da Panair (Conversando no bar). In: NASCIMENTO, Milton. Minas. Rio de Janeiro: EMI/ODEON, 1975. 1 CD: digital, estéreo. 61.192.406

NASCIMENTO, Milton; BRANT, Fernando. Idolatrada. In: NASCIMENTO, Milton. Minas. Rio de Janeiro: EMI/
ODEON, 1975. 1 CD: digital, estéreo. 61.247.740

NASCIMENTO, Milton; BRANT, Fernando. Ponta de areia. In: NASCIMENTO, Milton. Minas. Rio de Janeiro: EMI/ODEON, 1975. 1 CD: digital, estéreo. 61.247.731

NASCIMENTO, Milton; BRANT, Fernando. Promessas do sol. In: NASCIMENTO, Milton. Geraes. Rio de Janeiro: EMI/ODEON, 1975. 1 CD: digital, estéreo 61.192.422

NASCIMENTO, Milton; HOLLANDA, Francisco Buarque de. O cio da terra. In: NASCIMENTO, Milton. Geraes. Rio de Janeiro: EMI/ODEON, 1976. 1 CD: digital, estéreo. 60.299 .355

NASCIMENTO, Milton; HOLLANDA, Francisco Buarque de. Primeiro de maio. In: NASCIMENTO, Milton. Geraes. Rio de Janeiro: EMI/ODEON, 1976. 1 CD: digital, estéreo. 60.299 .231

NASCIMENTO, Milton; VELOSO, Caetano. Paula e Bebeto. In: NASCIMENTO, Milton. Minas. Rio de Janeiro: EMI/ODEON, 1975. 1 CD: digital, estéreo. 61.247.758

NORA, Pierre. Les lieux de mémorie. Paris: Editions Gallimard, 1992.

OSTROWER, Fayga. Criatividade e processos de criação. 19 ed. Petrópolis: Vozes, 1987.

SADIE, Stanley. The New Grove Dictionary Grove of Music and Musicians. 2nd ed. V. 26. London: MacMillan, 2001.

SCHULZ, Bruno. Sanatório sob o signo de Clepsidra. In: Sanatório. Rio de Janeiro: Imago, 1994. p. 157-183.

SOUZA, Alberto Carlos de. A cidade de Roma e seus (en) cantos. Entrevista concedida por Tereza Dell'acqua em 26 de setembro de 2009.

SOUZA, Beatriz de Paula. Mães contemporâneas e a orientação dos filhos para a escola. In: MACHADO, Adriana Marcondes; SOUZA, Marilene Proença Rebello (Orgs.). Psicologia escolar: em busca de novos rumos. São Paulo: Casa do Psicólogo, 1997. p. 181-187.

TRUFFAUT, François. O cinema segundo François Truffaut: textos reunidos por Anne Guillain. Rio de Janeiro: Nova Fronteira, 1990.

VIANNA, Luiz Fernando. Biografia e DVD levam Milton Nascimento de volta a Três Pontas. Rio de Janeiro: Folha de São Paulo [on line], 15 jun 2006. Disponível em: www.1.folha.uol.br/folha/ilustrada/ult90u66073.shtml. Acesso em 7 set 2009.

Submetido: 07/02/2014

Aprovado: 09/2014 